\title{
Material Properties of AZO/Si Thin Films After Hydrogenation and In-Situ Heat Treatment
}

\author{
Annett Thøgersen*, Smagul Karazhanov*, Chang Chuan You*, and A. Subrahmanyam** \\ * Institute for Energy Technology, Department of Solar Energy, Instituttveien 18, Kjeller, Norway \\ ** Indian Institute of Technology Madras, Chennai, India
}

Photovoltaics (PV) is becoming an increasingly important contributor to the supply of sustainable and renewable energy. Among the several approaches in PV for achieving high efficiencies and low cost factors, the thin film route has a high potential in realizing the projected demand [1-3]. The emerging concepts and the technology being developed in the third and fourth generation PV technologies require TCO, which, distinct from the Indium Tin Oxide (ITO), is capable of operating as both an active and passive layer. Presently, ITO is being widely used. However, it is constrained by its cost and availability. An alternative TCO having similar and more exotic properties is therefore a necessity. Doped and un-doped $\mathrm{ZnO}$ with its reasonably good knowledge base is a viable and apt choice [4-6]. ZnO:Al (AZO) films have shown to have a resistivity of the order of $10^{-4}$ $\Omega x \mathrm{~cm}$. Despite long time research, some challenges that are extremely important for solar cell applications of $\mathrm{ZnO}$ still remain to be resolved. The total efficiency of the solar cells, depends to a large extent on the TCO properties. Therefore it is critical to study the defects, surfaces and interfaces of novel TCO based on Zinc Oxide for high efficiency, fourth generation solar cells.

AZO and AZO:H films have been deposited on monocrystalline p- and n-type Si (100) substrates by an industrially designed DC magnetron sputtering equipment made by Leybold Optics. The atomic structure and composition of the AZO and AZO:H films have been studied with High Resolution Transmission Electron Microscopy (HRTEM), Energy Dispersive Spectroscopy (EDS), and X-ray Photoelectron Spectroscopy (XPS), and compared to electrical and optical measurements. As seen in Figure 1, the AZO films are evenly sputtered onto the Si substrates. However, a small interfacial $\mathrm{SiOx}$ layer is still present at the AZO/Si interface. EDS analysis shows only small changes in concentration through the AZO layer. However, there are some small differences in the concentration between the AZO sputtered on p-type Si compared to n-type. After hydrogenation of the samples, changes in the electrical measurements have been observed. These changes will be discussed relating to the material properties examined using TEM and XPS. In addition, the structural and compositional changes occurring during in-situ heat treatment of the samples will be presented in detail.

References

[1] K. Zweibel in Thin Film Solar Cells, pp 427- 462 (Wiley, 2006).

[2] L.L.Kazmerski, J Electron Spectr and related Phenomena, Vol. 150 (2006) 105.

[3] A. Bentzen, A. Holt. Overview of phosphorus diffusion and gettering in multicrystalline silicon. Mater. Sci. Eng. B. 159-60, 228-234 (2009).

[4] K.Ellmer, A.Klein and B. Rech. Transparent conducting Zinc oxide. (Springer, 2008).

[5] S.Z. Karazhanov, P. Ravindran, A. Kjekshus, H. Fjellvag, B.G. Svensson. Phys. Rev. B. 75, 155104 (2007).

[6] E.V. Monakhov, A.Y. Kuznetsov, B.G. Svensson. J. Phys. D, Appl. Phys. 42, 153001 (2009)

[7] This research was supported by the INDNOR program at the research council, nr. 205471. 
TABLE1: Composition of A1, Zn, and O, calculated from EDS spectra.

\begin{tabular}{llll}
\hline P-doped Si & Al (at. \%) & Zn (at. \%) & O (at. \%) \\
\hline 1 & 2,42 & 54,17 & 43,42 \\
2 & 2,46 & 53,63 & 43,91 \\
3 & 2,63 & 53,40 & 43,97 \\
4 & 2,54 & 51,60 & 45,86 \\
Whole layer & 2,56 & 52,84 & 44,60 \\
\hline N-doped Si & & & \\
\hline 1 & 2,25 & 57,67 & 40,08 \\
2 & 2,38 & 57,18 & 40,43 \\
3 & 2,64 & 57,98 & 39,38 \\
4 & 2,50 & 56,49 & 41,01 \\
Whole layer & 1,5 & 55,33 & 43,16 \\
\hline
\end{tabular}

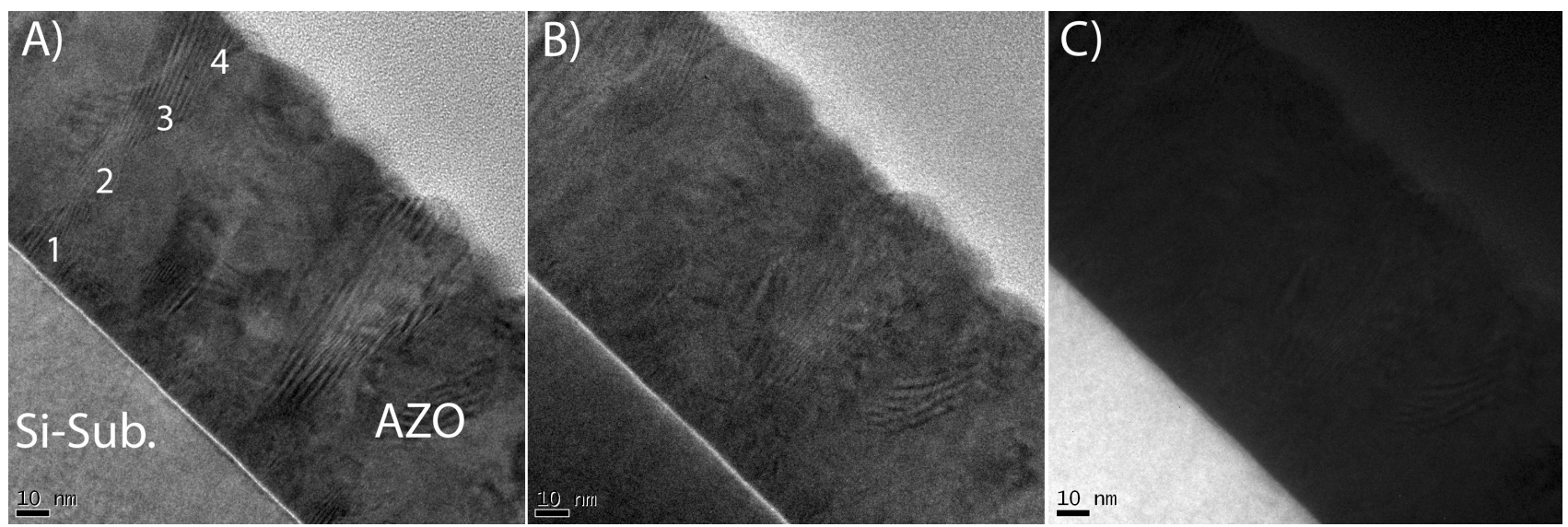

FIG. 1. AZO on p-doped Si substrate.A) HRTEM image (the numbers shows the area of EDS spectrum analysis), B) EFTEM image using the plasmon peak of $\mathrm{SiOx}(23 \mathrm{eV})$, and C) EFTEM image using the plasmon peak of $\mathrm{Si}(16 \mathrm{eV})$. 